\title{
Broilers (Gallus gallus) are less stressed if they can smell a mother odorant
}

\author{
I. Madec $^{1 \#}$, J.F. Gabarrou ${ }^{2}$, D. Saffray ${ }^{1}$ and P. Pageat ${ }^{1}$ \\ ${ }^{1}$ Pherosynthese Research Institute, le Rieu Neuf - 84490 Saint Saturnin Les Apt - France \\ ${ }^{2}$ E.I. Purpan, 75 voie du TOEC - 31076 Toulouse - France
}

\begin{abstract}
Performance, physiological and behavioural parameters of two groups of domestic chickens were compared. Chickens were raised in classical commercial conditions in buildings housing 12000 birds. One group acted as a control, while the environment of the other was perfused with MHUSA (Mother Hens' Uropygial Secretion Analogue), a synthetic analogue of a mother-hen odorant secretion which has shown its potential in reducing stress-related reactions in chickens. At the end of the rearing period the animals treated, appeared less stressed, as determined by a range of behavioural and physiological parameters. Even if there was no treatment effect on live weight, the carcasses of MHUSA treated animals were heavier and showed less scarring from fights. The influence of MHUSA was proven when it was removed from the atmosphere. Sex and age appeared to have an importance with regard to the action of MHUSA on the number of suffocated animals. There were no differences between the two groups in a variant of the tonic immobility test. Thus this semiochemical appears to have a positive effect on broiler welfare.
\end{abstract}

Keywords: Broilers, welfare, behaviour, physiology, semiochemical

\# Corresponding author. E-mail: imadec@pherosynthese.com

\section{Introduction}

A secretion from the uropygial gland of mother hens has been isolated on poultry (Gallus gallus) in natural conditions (mother with her chicks). This secretion shows a chemical pattern comparable to the appeasing pheromones discovered in mammals (pigs, horses, dogs), which have an appeasing effect on their young (Moltz \& Leet, 1981; Mc Glone \& Anderson, 2002; Pageat \& Gaultier, 2003). The native secretion, composing of fatty acids, is produced continuously from four days before hatching until separation occurs. A synthetic analogue called MHUSA (Mother Hen Uropygial Secretion Analogue; Pat. PCT/EP03/007144) has the same chemical composition as the native secretion. Therefore, MHUSA has the potential to reduce stress in domestic chickens, in particular under farming conditions (Madec et al., 2006; 2008). In poultry, behavioural parameters related to stress have been widely studied to assess welfare. These parameters are either in relation with natural conditions (Maria et al., 2004) or with pure behaviour (Roden \& Wechsler, 1997). The majority of these results come from small-scale studies. They allow the observer to take into account the large number of parameters but are very time consuming (Campo et al., 2000). It appeared to us that it would be of great interest to have criteria that characterize stress related behaviour in classical husbandries, but of an easy use, considering the large number of animals. It has been shown that correlations exist between behaviour in response to stress and physiological parameters such as the heterophil/lymphocyte ratio (HLR) (Puvaldolpriod \& Thaxton, 2000) and corticosterone level (Post et al., 2003). Performance parameters are also related to stress. Lower growth curves may be observed (Tankson et al., 2001) and the number of downgraded animals (i.e. suffocated or marks on the body) could be higher (Buitenhuis et al., 2002). It appears that these parameters may be utilized to assess behaviour related to stress when a large number of animals has to be studied. The starting hypothesis is that MHUSA has an appeasing effect on chicks, and thus, that the impact of stress should be reduced when using MHUSA. A trial has been designed, firstly to evaluate the impact of MHUSA on stress parameters related to behaviour, and secondly to evaluate its possible use as a tool for further studies.

\section{Materials and Methods}

Two adjoining broiler production buildings of $1200 \mathrm{~m}^{2}$ each were chosen because of their structure and constant production figures. A total of 24000 birds (2/3 males, 1/3 females, strain ROSS 308) were reared in each house. Birds were one day old upon arrival. Each building was separated into two sections: 
one for the males and one for the females. Females were slaughtered on day 40 and males on day 52. From day 40 to day 52, males were raised using $100 \%$ of the floor space. Food and water were provided ad libitum. The litter, composed of wood shavings, was fresh on day 0 and lasted for the entire batch. Buildings were of the Louisiana type: no enrichment nor cages, temperature was controlled using gas heaters or outdoor temperature using automatic blinds. Light schedule was six hours of continuous dark and 18 hours of continuous light per 24 hours. Six hours before transport to slaughter food was withheld from the chickens.

Two treatments were compared using a double blind procedure (until the analysis was completed all personnel involved in the trial were unaware of which group received the placebo or the MHUSA). For the treatment, the atmosphere of the crates was saturated with either MHUSA or a placebo of MHUSA (which acts as control) as described by Madec et al. (2006; 2008). Treatment began on the day prior to the arrival of the chicks (D-1). Each building received a different treatment. We chose this experimental design in order to avoid any cross-contamination of the odour chemicals under test between adjoining buildings. The analogue of the hen's scent was incorporated in macromolecular gelatine blocks (Nicols S.A., 59980 Bertry, France) and was identical to the treatment tested in previous field trials (Madec et al., 2006; 2008). The gelatine matrix was consisted of water (>90\%), a non-ionic surfactant (4\%) and a gelling gum (3\%). The control and MHUSA blocks had the same visual characteristics, but the Control block consisted of only the matrix whereas the MHUSA block contained 2\% of the active substance (MHUSA). On day 28 the blocks were replaced by new ones. The treated building was called, "MHUSA" and the other, "control" (placebo). Because only a double wall separated the two adjoining buildings, they were considered as two identical houses inside a unique unit. The two houses were similar, and met the objective of the study, viz. identical building in the same season (same temperature, hygrometry and light). Moreover, animals were comparable because of their genetic makeup. Therefore, the statistical unit considered was the chicken, not the building.

Four groups of parameters were studied. The first group took into account the general performance of the birds in the form of their live weights (LW) and carcass weights (CW). The second group of parameters related to visual features of the slaughtered birds (percentage of downgraded birds). Animals were downgraded because of death through suffocation during transportation or because they were scratched (i.e. marks on the body). On the day of departure for the slaughterhouse, two further tests of stress were carried out: a physiological assay and a behavioural test of fear (third group of parameters). These were carried out in the same order with both tests being conducted on the same birds in all cases, with 100 birds from each house (50 males and 50 females) being sampled. Each animal was captured, the behavioural test was performed, and then blood was collected. A behavioural test was adapted from the classic Tonic Immobility test (Gallup, 1977). Each animal was captured and placed on its back in a small hammock for a maximum of 60 seconds. Once the animal was on its back, it was restrained gently (placing one hand over its chest) for 10 seconds and then released but fixed by the experimenter's gaze (from a distance of one metre, eye to eye contact was made). The time taken for the bird to stand up was recorded with a censor applied after 60 seconds. At this stage the bird was considered as 'still'. A maximum of 60 seconds was chosen because it did not appear possible to stay in the houses while performing the test for 300 seconds (required by the original test from Gallup, 1977) for each studied animal. The physiological blood parameters consisted of HLR and corticosterone levels. The blood was collected via the wing vein and stored in EDTA tubes. HLR was estimated from blood film smears using May-Grunwald and Giemsa stains (Lucas \& Jamroz, 1961). One hundred leucocytes (granular and non-granular) were counted. Corticosterone levels were determined on plasma using a Radio Immuno Assay method (De Jong et al., 2001). Behavioural observations and blood sampling were performed at night (same conditions in each house).

Statistical analysis was performed using the Statistica $5.0 \AA$ software (Statsoft Ltd, UK). Data were analyzed by comparing means using the Student's t-test, or the Mann-Whitney U-test when appropriate. Results are considered significant if $\mathrm{P}<0.05$.

\section{Results}

Transport to the slaughterhouse took place on the same day for each building: on day 52 for males and on day 40 for females, both at night. Carcass weights of the control birds were lighter compared with the MHUSA treated birds $(\mathrm{P}<0.001$, Table 1$)$. 
Table 1 Effect of mother odorant on mean ( \pm s.d.) live and carcass weights (g) of chickens

\begin{tabular}{lcccc}
\hline & \multicolumn{2}{c}{ Males } & \multicolumn{2}{c}{ Females } \\
\cline { 2 - 4 } & Control & MHUSA & Control & MHUSA \\
\hline Live weight & $2843 \pm 501$ & $3086 \pm 752$ & $1607 \pm 326$ & $1693 \pm 338$ \\
Carcass weight & $2062^{\mathrm{a}} \pm 389$ & $2221^{\mathrm{b}} \pm 411$ & $1098^{\mathrm{c}} \pm 210$ & $1133^{\mathrm{d}} \pm 219$ \\
& & & \\
\hline $\begin{array}{l}\text { a, b, c, d } \text { Row means (within sex comparison) with different superscripts differ significantly at P }<0.05 . \\
\text { MHUSA - Mother Hen Uropygial Secretion Analogue }\end{array}$
\end{tabular}

Final live body weights of both males and females were lower, but not significantly, in the control group compared to the MHUSA. The percentage of scratched animals was lower $(\mathrm{P}<0.001)$ in the MHUSA (Table 2): $8 \%$ vs. $22 \%$ and $10 \%$ vs. $19 \%$ for males and females, respectively. There were more suffocated females in the control group than in the MHUSA group: 6.36\% vs. 3.25\% ( $\mathrm{P}<0.001)$, whereas there were more suffocated males in the MHUSA group: $1.36 \%$ vs. $1.11 \%(\mathrm{P}<0.05)$.

Table 2 Effect of mother odorant on percentage downgraded birds at slaughter

\begin{tabular}{lllll}
\hline & \multicolumn{3}{c}{ Males } & \multicolumn{2}{c}{ Females } \\
\cline { 2 - 4 } & Control & MHUSA & Control & MHUSA \\
\hline Suffocated (\%) & $1.11^{\mathrm{a}} \pm 0.11$ & $1.36^{\mathrm{b}} \pm 0.12$ & $6.36^{\mathrm{c}} \pm 0.24$ & $3.25^{\mathrm{d}} \pm 0.18$ \\
Scratched (\%) & $22.0^{\mathrm{a}} \pm 0.41$ & $8.0^{\mathrm{b}} \pm 0.27$ & $19.0^{\mathrm{c}} \pm 0.39$ & $10.0^{\mathrm{d}} \pm 0.30$ \\
\hline a, b, c, d Row means (within sex comparison) with different superscripts differ significantly at $\mathrm{P}<0.05$.
\end{tabular}

Comparison of HLR between both groups showed a lower $(\mathrm{P}<0.01)$ ratio for the MHUSA than for the control group (Table 3). Corticosterone plasma levels were higher in the control group $(\mathrm{P}<0.05)$ for the males whereas no differences were observed among the females (Table 3).

Table 3 Effect of mother odorant on heterophil/lymphocyte ratio and corticosterone levels (ng/mL plasma) in the blood of chickens at the end of the study

\begin{tabular}{lllll}
\hline & \multicolumn{2}{c}{ Males } & \multicolumn{2}{c}{ Females } \\
\cline { 2 - 5 } & Control & MHUSA & Control & MHUSA \\
\hline $\begin{array}{l}\text { Heterophil/Lymphocyte } \\
\text { Corticosterone }\end{array}$ & $1.10^{\mathrm{a}} \pm 1.26$ & $0.81^{\mathrm{a}} \pm 0.57$ & $0.85^{\mathrm{b}} \pm 0.08$ & $0.77^{\mathrm{c}} \pm 0.10$ \\
& $3.40^{\mathrm{a}} \pm 2.23$ & $2.60^{\mathrm{b}} \pm 1.37$ & $2.35^{\mathrm{c}} \pm 0.49$ & $2.27^{\mathrm{c}} \pm 0.70$ \\
\hline $\begin{array}{l}\text { a, b, }{ }^{\mathrm{c}} \text { Row means (within sex comparison) with different superscripts differ significantly at P }<0.05 . \\
\text { MHUSA - Mother Hen Uropygial Secretion Analogue }\end{array}$
\end{tabular}

The analysis of the behavioural test did not show any difference among groups. We observed comparable means of 39.6 seconds for males and 41.2 seconds for females before they first move.

\section{Discussion}

Our results demonstrated that, when housed under standardized commercial conditions, broilers exposed to MHUSA showed a lower level of stress compared to the control group. Intensity of stress was 
assessed by measuring physiological and blood parameters. The growth, as a physiological parameter, was assessed through carcass weights. These differences between the two groups are in accordance with the results found in other experiments relative to the consequences of stress on performances (Zulfiki et al., 2002), in particular when using MHUSA (Madec et al., 2006; 2008). This may be due to a lower activity of the MHUSA treated group, which tends to consume less energy and then have a lower catabolism under stressors. This is in accordance with previous observations by Siegel (1995). Blood parameters confirmed the difference of stress between MHUSA and the control. Birds from the MHUSA group showed lower HLR and corticosterone level. Stressed poultry having such physiological and haematological modifications tend to display feather pecking (Buitenhuis et al., 2002), which is consistent with our findings regarding corticosterone levels and the number of scratched animals in the control group. In poultry several needs have been described and have to be satisfied to ensure the welfare of the birds. Access to water and dust baths, an appropriate density, a group size that allows individual recognition are necessary for the stabilization of hierarchical dominance and socialization to humans (Jones, 1987). If we compare this with the situation observed in the studied houses, several needs appear to be unsatisfied, creating stress-inducing surroundings. On the one hand, the density ( $20 \mathrm{birds} / \mathrm{m}^{2}$ ) was acceptable according to the current European legislation. On the other hand, there were no water or dust bathing facilities. Except for the provided compacted litter, birds had no access to a real dust bath, as described by Vestergaard et al. (1999). Because we had no option of modifying the habits of the employees, the socialization to humans was difficult to assess and we cannot conclude on their involvement in possible stressing events. The crucial point seemed to be the size of a group. As observed on commercial poultry farms, a large group size (12000 chickens in each house) does not allow the easy establishment of dominance (Barnard \& Burck, 1979). It is almost impossible for the birds to recognize their flock-mates individually (Appleby et al., 1989). This situation is especially critical for male chickens. Studies on the behaviour of wild chickens showed that intraspecific aggressiveness of male chicks begins to develop from the age of one week, becomes stronger as well as more frequent after three weeks and is systematically induced by proximity to other males (Kruijt, 1964). In domestic chickens the aggressive reactions are delayed when there is habituation to the group (Evans, 1967). According to the technical management of our population, both habituation and hierarchical organization could not occur because of the size of the groups. This situation is responsible for inducing social stress within the studied population. Our results, which showed a difference among sexes in the rate of suffocated animals, can be analyzed as a consequence of a different social stress among males and among females. During transportation the chickens were kept in crates without MHUSA, and the density of individuals from the same sex was dramatically increased, constituting another cause of stress (Nidjam et al., 2004). Female chickens are used to living in packs and closeness does not induce aggressive reactions, nor stress (Evans, 1967). Meanwhile, the longer breeding period for males represents another source of stress, as demonstrated by Jensen \& Tates (1993). Females and males were transported without MHUSA, and the females who did not experience the social stress did not show any agitation, whereas the males, stressed by the proximity to possible competitors, did. This is assessed by the difference in the corticosterone level between treatments, that was observed only in males (Table 3), and probably causing some of them to die from suffocation. This result raises the question of transporting male chickens with MHUSA to prevent aggressive reactions. The fights between chickens were assessed according to downgraded carcasses because of scratches. Results observed for both sexes highlighted the efficacy of MHUSA in controlling stress and aggressiveness. If fights among males are common, male chickens attack females too (Millman et al., 2000). These aggressions, enhanced by closeness, can be induced by different behaviours and especially by alarm stimulations (Hinde, 1975). If less stressed, as shown by blood and physiological parameters, birds are less likely to show alarm attitudes. They therefore fight less. We did not observe any difference between treatments regarding the behavioural test. According to the literature, this test is related to acute fear and evaluates the freezing reaction, which is a particular adaptive response and not a sign of chronic stress (Zulkifi et al., 2002). Induction of stress is indeed different from fear (Hughes \& Black, 1974). This test may not be appropriate in evaluating differences between stressed and non-stressed chickens. Another explanation could be related to the way we have modified the original test. Because we were not allowed to stay inside the houses for too long, we decided to limit our test to 60 seconds instead of the 300 seconds used in the test by Gallup (1977). Our evaluation time was perhaps too short to observe any difference between the groups. Our starting hypothesis of a reduction of stress using MHUSA is thus consistent with these results, but raises the question of the use of an olfactory stimulation in chickens. Birds have been shown to have functional, well developed, olfactory 
bulbs (Jones \& Carmichael, 1999). Different studies have shown an existing chemical communication between birds (Kolattukudy et al., 1987; Bohnet et al., 1991). In chickens, the secretion of alarm pheromones has been hypothesized as a consequence of the increase of the diameter of the uropygial gland (Bandyopadhyay et al., 1990). Sexual pheromones have been described in ducks, geese (Nicolaides, 1974; Bohnet et al., 1991) and in Japanese quail (Abalain et al., 1984). The behavioural and biological effects of MHUSA are similar to the ones observed in mammals when using appeasing pheromones, which decrease aggressive and fear reactions, and the cortisol blood level, and improve growth (Mc Glone, 1984; Pageat \& Gaultier, 2003; Kooni et al., 2005). Considering these results and the context of uropygial secretion of nursing hens, we could consider this secretion as a putative chicken pheromone. This would have to be proven in further experiments, in particular regarding the specificity of this putative pheromone.

\section{Conclusion}

This work shows that some parameters may be good indicators of stress behaviour. These parameters are easier to compute compared to a classical behaviour study such as scan sampling or focus sampling, in particular in commercial husbandries. The second main conclusion is that the studied MHUSA is effective in controlling stress in broilers living in intensive farming conditions.

\section{Acknowledgments}

Authors thank Pr D. Mills from Lincoln University UK and S. Prince, English teacher at EI Purpan of Toulouse France, for their help in English proof checking.

\section{References}

Abalain, J.H., Amet, Y., Daniel, J.Y. \& Floch, H.H., 1984. Androgen regulation of secretions in the sebaceous-like uropygial gland of the male Japanese quail. J. Endocrinol. 103, 147-153.

Appleby, M.C., Hughes, B.O. \& Hogarth, G.S., 1989. Behaviour of laying hens in a deep litter house. Br. Poult. Sci. 30, 545-553.

Bandyopadhyay, A., Dearhikari, H. Ranjit, A.H., \& Bhattacharyya, S.P., 1990. Adrenocortical influence on kinetics and lipid components of uropygial gland of immature chicks. Indian J. Exp. Biol. 28, 915-919.

Barnard, C.J. \& Burck, T., 1979. Dominance hierarchies and the evolution of individual recognition. J. Theor. Biol. 81, 65-73.

Bohnet, S., Rogers, L., Sasaki, G. \& Kolattukudy, P.E., 1991. Estradiol induces proliferation of peroxisomelike microbodies and the production of 3-hydroxy fatty acid diesters, the female pheromones, in the uropygial glands of male and female mallards. J. Biol. Chem. 266, 9795-9804.

Buitenhuis, A.J., Rodenburg, T.B., van Hierden, Y.M., Ask, B., Siwek, M., Cornelissen, S.J.B., Nieuwland, M.G.B, de Groot, P., Korte, S.M., Koene, P., Bovenhuis, H. \& van der Poel, J.J., 2002. Feather pecking behaviour and stress response in laying hens: a QTL analysis. 7th WCGALP, MontpellierFrance. p. 14.

Campo, J.L., Garcia Gil, M., Munoz, I. \& Alonso, M., 2000. Relationship between bilateral asymmetry and tonic immobility reaction or heterophil to lymphocyte ratio in five breeds of chickens. Poult. Sci. 79, 453-459.

De Jong, I.C., van Voorst, A., Erkens, J.H., Ehlardt, D.A. \& Blokhuis, H.J., 2001. Determination of the circadian rhythm in plasma corticosterone and catecholamine concentrations in growing broilers breeders using intravenous cannulations. Physiol. Behav. 74, 299-304.

Evans, R.M., 1967. Early aggressive responses in domestic chicks. Anim. Behav. 16, 24-28.

Gallup Jr., G.G., 1977. Tonic Immobility: the role of fear and predation. The Psychol. Rec. 1, 41-61.

Hinde, R.A., 1975. Le comportement animal. Tome 2. Presses Universitaires de France, Paris. pp. 626-627.

Hughes, B.O. \& Black, A.J., 1974. The effect of environmental factors on activity, selected behaviour patterns and fear of fowls in cages and pens. Br. Poult. Sci. 15, 375-380.

Jensen, P. \& Tates, F.M., 1993. Who needs 'behavioural needs'? Motivational aspects of the needs of animals. Appl. Anim. Behav. Sci. 37, 161-181.

Jones, R.B., 1987. Social and environment aspects of fear in the domestic fowl. In: Cognitive Aspects of Social Behaviour in the Domestic Fowl. Eds. Zayan, R. \& Ducan, J.H., Elsevier. pp. 82-149. 
Jones, R.B. \& Carmichael, N.L., 1999. Domestic chicks are attracted to a familiar odorant in a novel test situation: a brief report. Appl. Anim. Behav. Sci. 61, 351-356.

Kolattukudy, P.E., Bhonet, S. \& Rogers, L., 1987. Diester of 3-H fatty acids produced by the uropygial glands of female mallards uniquely during the mating season. J. Lipid Res. 28, 582-588.

Kooni, M., Yonezawa, T., Kikusui, T., Stafford, K., Pageat, P. \& Mori, Y., 2005. Synthetic pig appeasing pheromone relieves agonistic stress in adult female pigs. Proceedings of the $39^{\text {th }}$ Int. Congr. ISAE, Kanagawa, Japan. Eds. Kusunose, K. \& Shusuke, S., ISAE Publ., 132.

Kruijt, J.T., 1964. Ontogeny of social behaviour in Burmese red junglefowl (Gallus gallus spadiceus Bonnaterre). Behaviour Suppl., 12.

Lucas, A.M. \& Jamroz, C., 1961. Atlas of avian hematology. Agriculture Monograph 25, USDA, Washington D.C., USA.

Madec, I., Gabarrou, J.F., Guillaumey, D., Bougrat, L. \& Pageat, P., 2008. Are 35 days enought to observe a reduction of stress by using a hen's semiochemical analogue on chickens (Gallus gallus domesticus) housed under high density? Poult. Sci. 85, 2112-2116.

Madec, I., Pageat, P., Bougrat, L., Saffray, D., Falewee, C., Gervasoni, M.A., Bollart, A. \& Gabarrou, J.F., 2006. Influence of a semiochemical analogue on growing performances and meat quality of broilers. Poult. Sci. 87, 222-225.

Maria, G.A., Escos, J. \& Alados, C.L., 2004. Complexity of behavioural sequences and their relation to stress condition in chickens: a non invasive technique to evaluate animal welfare. Appl. Anim. Behav. Sci. 86, 93-104.

Mc Glone, J.J., 1984 Olfactory cues and pig agonistic behaviour: evidence for a submissive pheromone. Physiol. Behav. 34, 195-198.

Mc Glone, J.J. \& Anderson, D.L., 2002. Synthetic pheromone stimulates feeding behaviour and weight gain in weaned pigs. J. Anim. Sci. 80, 3179-3183.

Millman, S.T., Duncan, I.H.J. \& Widowski, T.M., 2000. Male broiler breeder fowl display high levels of aggression toward females. Poult. Sci. 79, 1233-1241.

Moltz, H. \& Leet, M., 1981. The maternal pheromone of the rat: identity and functional significance. Phys. Behav. 26, 301-306.

Nicolaides, N., 1974. Skin lipids; their biochemical uniqueness. Science 186, 19-26.

Nidjam, E., Arens, P., Lambooij, E., Decuypere, E. \& Stegeman, J.A., 2004. Factors influencing bruises and mortality of broilers during catching, transport and lairage. Poult. Sci. 83, 1610-1615.

Pageat, P. \& Gaultier, E., 2003. Current research in canine and feline pheromones. The Veterinary Clinics 33, 187-211.

Post, J., Rebel, M.J. \& ter Huurne, A.A.H.M., 2003. Physiological effects of elevated plasma Corticosterone concentrations in broiler chickens. An alternative means by which to assess the physiological effects of stress. Poult. Sci. 82, 1313-1318.

Puvaldolpriod, S. \& Thaxton, J.P., 2000. Model of physiological stress in chickens, response parameters. Poult. Sci. 79, 363-369.

Roden, C. \& Wechsler, B., 1997. A comparison of the behaviour of domestic chicks reared with or without a hen in enriched pens. Appl. Anim. Behav. Sci. 55, 317-326.

Siegel, H.S., 1995. Stress, strains and resistance. Br. Poult. Sci. 36, 3-22.

Statsoft Ltd, 21-23 Mill Street, Bedford, MK40 3EU. United Kingdom.

Tankson, J.D., Vizzier Thaxton, Y., Thaxton, J.P., May, J.D. \& Cameron, A., 2001. Stress and nutritional quality of broilers. Poult. Sci. 80, 1384-1389.

Vestergaard, K.S., Damm, B.I., Abbott, U.K. \& Blidsoe, M., 1999. Regulation of dustbathing in feathered and featherless domestic chicks: the Lorenzian model revisited. Anim. Behav. 58, 1017-1025.

Zulkifli, I., Gilbert, J., Liew, P.K. \& Ginsos, J., 2002. The effects of regular visual contact with human beings on fear, stress, antibody and growth responses in broiler chickens Appl. Anim. Behav. Sci. 79, 103-112. 